\title{
TREZE TÍLIAS: ARTICULAÇÕES ENTRE MEMÓRIA SOCIAL E TURISMO CULTURAL
}

\author{
Marcos Teixeira de Souza*
}

\begin{abstract}
Resumo
A cidade de Treze Tílias (SC) exemplifica bem a relação entre memória social e turismo cultural como uma ponte, onde existe o trânsito de lembranças, silêncios e narrativas em uma sociedade. Fundador de uma colônia no oeste catarinense, o nome de Andreas Thaler converge essa interação, desenvolvendo o município, formado por muitos descendentes de Thaler e de outras famílias. Nessa perspectiva, por meio de um olhar etnográfico e bibliográfico, este artigo discute brevemente as categorias memória social e turismo cultural em relação à cidade de Treze Tílias.
\end{abstract}

Palavras-chave: Treze Tílias. Turismo cultural. Memória Social. Andreas Thaler.

* Doutorando em Sociologia - IUPERJ/UCAM. Professor da Universidade Estácio de Sá (UNESA) e da Universidade do Grande Rio (Unigranrio).Email: prof1marcos@hotmail.com. 


\section{Introdução}

O presente artigo é oriundo de uma pesquisa bibliográfica e etnográfica realizada em julho de 2012, em Treze Tílias, durante minha pesquisa exploratória ao adentrar no curso de doutorado em Sociologia, sendo recém-egresso de um mestrado em Letras e Ciências Humanas,. Nesse momento, pude ter contato com algumas discussões em torno da noção de memória social nas interações e grupos sociais.

O termo cidade pode ser traduzido, essencialmente, por duas concepções: como um lugar em oposição à área rural; ou como uma entidade político-administrativa delimitada geograficamente. Essas duas concepções não negam uma terceira possível: a de entender cidade como um grupo social ligado e delimitado pelas memórias, imagens e lembranças sociais comuns aos seus respectivos membros, conforme podemos ver em Anderson (2008) em Comunidades Imaginadas: reflexões sobre a origem e difusão do nacionalismo. Nesse ponto, é importante considerar o diz Robert Park (1916) sobre a categoria cidade:

A verdade, entretanto, é que a cidade está enraizada nos hábitos e costumes das pessoas que a habitam. A consequência é que a cidade possui uma organização moral bem como uma organização física, e estas duas interagem mutuamente de modos característicos para se moldarem e modificarem uma a outra. É a estrutura da cidade que primeiro nos impressiona por sua vastidão e complexidade visíveis (PARK, 1916, p.32).

Apesar dessa terceira via de entendimento ser mais imaginária que concreta, os estudos sobre memória social têm colaborado para que a cidade seja enxergada pela sua dimensão imagético-memorativa, em que ela é vista por seus membros pelo espectro da noção de pertença a um determinado grupo em detrimento a outro.

\section{Treze Tílias, uma cidade à la Andreas Thaler}

Considerado o Tirol brasileiro, a cidade de Treze Tílias é vista, em geral, pelos seus moradores e por muitos catarinenses como um "pedacinho" da Áustria em solo brasileiro, considerando que essa pequena cidade, com menos de sete mil habitantes, segundo dados do Censo 2010 (IBGE), detém um consulado 
da Áustria, contexto, a priori, atípico para uma entidade que geralmente se localiza em capitais ou grandes cidades, mas que encontra razoabilidade quando verifica-se o fluxo da entrada de austríacos na região e a saída de treze-tilenses para a Áustria.

É digno de nota que essa cidade do oeste catarinense possui um conjunto de dados positivos quanto à qualidade de vida e ao progresso social. Mas nossa atenção, neste artigo, se atém mais a relação memória social e turismo cultural, o que ora propomos discutir.

O município de Treze Tílias, que em 2013 completou o octogésimo aniversário de fundação de sua outrora colônia, ilustra bem um debate em torno da relevância dos estudos e teorias sobre memória social como constructo teórico importante para entender uma sociedade e suas características sociais, culturais, econômicas, entre outras.

Obviamente, não se deseja afirmar, categoricamente, que uma sociedade possa ser explicada somente por sua memória social, mas que existem - se não em todas, em grande parte - conteúdos explicativos quando atenta-se para a memória social, sobretudo em lugares que buscam preservar suas tradições e valorizar seu passado, como é o caso de Treze Tílias.

Os estudos sobre memória social devem-se à contribuição, primordialmente, de escritores franceses, que escreveram na primeira metade do século XX, buscando compreender como o passado inseria-se no contexto de suas respectivas épocas. Esses teóricos enxergaram o passado como elemento mais próprio do tempo presente do que paradoxalmente do tempo pretérito.

Pierre Nora (1984), Jacques Le Goff (1990), Michael Pollak (1989; 1992), Maurice Halbwachs (2006), entre outros autores evidenciaram em seus escritos o papel da memória social como um fato social construído, em geral, por um grupo social hegemônico em uma determinada sociedade. $\mathrm{O}$ silêncio, objeto de análise social outrora esquecido, ganha relevo na compreensão de fenômenos sociais.

Trazendo à tona a questão do silêncio na discussão sobre o papel da memória social, Pollak (1989) abriu espaço para conceber a memória como um instrumento de manipulação no entorno social. Assim, memória e silêncio podem ser consideradas como marcas reveladoras de poder político, social e cultural. Em outras palavras, há, em muitas ocasiões, uma intencionalidade em marcar 
ou esconder uma memória no seio da sociedade. Treze Tílias não foge a essa característica.

A imigração para a então colônia de Treze Tílias deu-se por meio do empreendimento arquitetado pelo então Ministro da Agricultura da Áustria, o senhor Andreas Thaler, que, diante de uma Europa do pós-primeira guerra mundial, viu seu país vivenciar uma grave instabilidade econômica, buscando uma alternativa para evitar um cenário vindouro de escassez e adversidades. Descreve Martin et al (2011, p. 15):

Entre 1921 e 1937, conforme estatísticas, mais de 75.000 austríacos, entre homens e mulheres, emigraram para além-mar, dos quais 31.000 para os EUA, quase 14.000 para o Brasil e 11.000 para a Argentina. A grande maioria deixara a Áustria, na Primeira República, por razões socioeconômicas.

No século XIX e nas primeiras décadas do XX, a propaganda do Brasil como um destino promissor animara muitos austríacos e, nesse ponto, a ação de Thaler foi decisiva para a promoção, organização e realização da emigração para a colônia que ele fundara, a Dreizehnlinden (Treze Tílias). Cabe destacar que houve, também, vários relatos das dificuldades na travessia do Atlântico, casos de morte, desencontro de famílias e obstáculos diversos nas matas catarinenses.

Cabe lembrar que a emigração de europeus está envolta a uma política incentivada pelo governo brasileiro a partir da segunda metade do século XIX e das primeiras décadas do XX, que objetivava, entre outras metas, substituir a mão de obra africana pelo trabalho de imigrantes. Além disso, como pano de fundo, há também as chamadas teses racialistas, que estavam no bojo dessa política e que via nas levas de imigrantes europeus a possibilidade de embranquecer o Brasil, um sinônimo esdrúxulo de que com tal política pudesse civilizar o país.

Fundada no dia 13 de outubro de 1933, por Andreas Thaler, que na ocasião era, então, Ministro da Agricultura da Áustria, a colônia Treze Tílias paulatinamente desenvolveu-se com a chegada desses imigrantes austríacos tiroleses, que, sob o comando de Thaler, organizaram a colônia, tendo o trabalho agrícola como caminho para melhorar as condições de vida.

A morte de Andreas Thaler deu-se em um dia chuvoso na cidade. Segundo Martin et al (2011), ele e outros compatriotas acidentaram-se na ponte sobre o Rio Peixe. As intensas águas, 
provocadas pela forte chuva, irromperam sobre a ponte e levara-os correnteza abaixo. Escrevem Martin et al (2011, p. 214):

Com o auxílio dos demais, todos se livraram da forte correnteza; somente Thaler, provavelmente ferido por um pedaço de madeira, teria sido levado, inconsciente, pelas águas. Até as quatro horas da manhã foram feitas buscas desesperadoras peara encontrá-lo, continuando no dia seguinte sem qualquer sucesso. Somente em $1^{\circ}$ de julho, por volta do meio-dia, foi possível encontrar e recolher o corpo, preso a raízes, a uma distância aproximada de um quilômetro abaixo do local do acidente. Percebiam-se graves ferimentos na cabeça. No domingo, 2 de julho de 1939, o corpo de Andreas Thaler, sob forte comoção, foi sepultado no cemitério de Dreizehnlinden.

Como percebe-se abaixo, a morte de Andréas Thaler trouxe muita dor para os colonos, que tinham nele a figura de um grande empreendedor. Continua Martin et al (2011, p. 214):

De um dia para outro a colônia havia perdido o seu líder. Dessa forma, Andreas Thaler sacrificou também a vida à sua obra, a colônia de Dreizehnlinden, que se encontrava em vias de crescimento. Não apenas no Brasil, mas também na distante pátria Áustria, a qual tanto amou e pela qual trabalhou com denodo e afinco, não se apagará a lembrança desse agricultor das montanhas do Tirol, que atingiu altos cargos e dignidade graças a seu talento incomum, sua dedicação e seu caráter impoluto, dedicando-se com absoluta abnegação à sua ação pioneira. Em Treze Tílias, foi-lhe erigido um monumento.

A morte de Andreas Thaler não representou o fim da colônia. Ele deixou filhos, parentes, amigos e admiradores de sua luta. E foram estes que empenharam-se para a preservação da colônia, que teria em Thaler uma expressão de desbravamento e trabalho, ao lado de outras famílias imigrantes. Nesse aspecto, ao longo das décadas, justifica-se a realização, anualmente, de festas comemorativas relacionadas à imigração para Treze Tílias, tornando o nome de Thaler cada vez mais significativo para aquele grupo social e sendo o passado uma categoria importante para ser acionado por estes.

Em Sociologia, um dos tópicos que ensejam muitos debates e pesquisas é o da memória social, porque permite-nos buscar as correlações entre passado, presente e futuro e problematizar essas categorias como não lineares. Passado, presente e futuro 
encontram-se entrelaçados, de modo que a evocação do passado, por exemplo, engloba o presente nas relações sociais construídas no cotidiano de uma sociedade. Uma dessas expressões visíveis é criação de marcos de lembranças, que oportunizam que os indivíduos de uma sociedade olhem para o seu passado, bem como norteiem seu futuro.

Convém notar que após a morte de Andreas Thaler dá-se, paulatinamente, o nascimento da memória deste entre trezetilenses. Quem vai a Treze Tílias, a turismo ou para lá estabelecerse, não demora a conhecer a história desse homem. Assim, as marcas da memória social estão presentes na cultura material e imaterial da localidade e são extremamente importantes na formação identitária do treze-tilense. É oportuno citar Castells (2008, p. 22), que concebe identidade:

No que diz respeito a atores sociais, entendo por identidade o processo de construção de significado com base em um atributo cultural, ou ainda um conjunto de atributos culturais inter-relacionados, o(s) qual(ais) prevalece $(\mathrm{m})$ sobre outras fontes de significado.

Nessa concepção, a construção da identidade está atrelada a construir significados. A ótica de Castells (2008) dirige-se, assim, para um processo ativo por parte dos atores sociais. Em outras palavras, construir uma identidade implica no indivíduo mobilizar-se dentro de sua sociedade, e a cultura é uma das arenas onde o ator social construiria sua identidade. Por conter uma gama de significados e ser uma expressão intrínseca ao ser humano, a cultura constitui praticamente uma atividade em que se dá uma condição sine qua non para que os indivíduos estabeleçam fronteiras entre si e o outro, ocupando a etnicidade um dos aspectos importantes no tocante à manifestação identitária dos atores sociais.

$\mathrm{O}$ ato de nomear ruas, instituições públicas, eventos, praças, lugares etc. sinaliza uma ação de evocar e salientar uma memória que, nesse caso, é social. Ao escolher os nomes para os espaços citados, os indivíduos os nomeiam com no afã de constituir uma memória naquela respectiva localidade, isto é, de reverenciar uma situação ou evento, empoderar determinado grupo social etc. Os motivos para essa escolha são diversos, mas o objetivo relacionase com a memória social, que atua no contexto dos grupos sociais e revelam as estratégias de um grupo em perpetuar uma história. 
Em Treze Tílias, a principal marca de memória social é o castelo onde Thaler viveu e que tornou-se um museu, o Museu Municipal Ministro Andreas Thaler. A privilegiada posição topográfica e geográfica desse museu na cidade e sua arquitetura expressiva sintetizam bem a oportunidade de aliar turismo e memória construída ao redor desse castelo. Abreu (2008, p. 48), em seu artigo Patrimônios etnográficos e museus: uma visão antropológica, enfatiza que:

A sociedade ocidental moderna, no entanto, criou instituições específicas bastante complexas para guardar, proteger, promover e difundir acervos e registros coletados em diferentes sociedades. Tais instituições são, entre outras, arquivos, bibliotecas, museus, centros culturais e laboratórios de memória e documentação. Além disso, os pesquisadores-antropólogos, no caso de acervos e registros etnográficos - são pessoas especialmente treinadas para reconhecer quais bens tangíveis ou intangíveis importam para configurar sistemas culturais nas sociedades estudadas.

Treze Tílias também apresenta outros lugares de memória, como o Parque do Imigrante, monumentos e uma série de atividades culturais, cujo mote é a memória social da imigração. Além disso, um importante expoente é a Tirofest, festa que ocorre todos os anos, no mês de outubro e, com duração de mais de uma semana de comemoração, envolve o aniversário da colônia, no dia 13 de outubro e tem na figura de Andreas Thaler a mentoria de um plano que obteve êxito, apesar das dificuldades iniciais enfrentadas pelos pioneiros à época. Nesse ponto, ao longo do tempo, o turismo cultural fez-se e faz-se, também, em perfilar localmente não só as tradições e festas, mas também em associar o percurso dessa sociedade, cujos índices de desenvolvimento humano da cidade demonstram, entre outros, o sucesso da imigração. A Tirolerfest reúne muitos turistas, brasileiros e estrangeiros, tendo como ponto alto do evento o desfile da imigração, que ocorre na principal rua da cidade.

Para a Sociologia, esses indícios colaboram no entender como uma sociedade se formou e mantém sua relação com o passado, considerando-o importante ou não na construção identitária. Em maior ou menor grau, sociedades e indivíduos olham para seu pretérito. Principalmente, a tônica ou o descaso em relação a um passado constitui um objeto de pesquisa relevante para a Sociologia, porque, além da questão identitária, envolve classificar, 
hierarquizar o que é tido como mais importante, ou seja, o que deve ser lembrado e o que deve ser esquecido pelas gerações vindouras que comporiam determinada sociedade.

\section{Turismo cultural e memória social: uma articulação intrínseca}

Partindo da definição de turismo cunhada pela Organização Mundial de Turismo, pode-se alocar e estudar esse fenômeno não só sob o prisma de uma atividade de impacto na economia, mas também na sociedade ou, em outras palavras, como uma atividade humana cuja dinâmica tem sido alvo da Sociologia.

O turismo compreende as atividades realizadas pelas pessoas durante suas viagens a e estadias em lugares diferentes de seu entorno habitual, por um período de tempo consecutivo inferior a um ano, tendo em vista lazer, negócios ou outros motivos. (OMT, 1995, p. $1)$.

O interesse da Sociologia pela temática do turismo ainda é recente e tal particularidade deve-se a vários fatores, entre eles os mais visíveis são, primeiramente, a Sociologia, seja a realizada no Brasil ou fora dele, que debruçou sua atenção para as desigualdades entre os homens, a religião, as implicações da moral sobre a ordem social; a construção de uma memória social, o etnocentrismo, o multiculturalismo, entre outras temáticas, as quais, de certa forma, puseram em segundo plano o lazer ou o turismo como uma questão relevante para essa área do conhecimento.

Dentro dessa perspectiva, é pertinente lembrar que as sociedades industriais, investigadas pelos primeiros sociólogos eram geralmente sociedades que orbitavam em torno do trabalho, considerando-o como reprodutor de desigualdades sociais ou diferenciador entre os atores sociais. A categoria lazer entraria só mais tarde como um contraponto ao trabalho, nos anos 1960 e 1970, com as pesquisas de Joffre Dumazedier $(1976$; 1999) e Stanley Parker (1978), entre outras contribuições. Já os estudos e pesquisas sobre o turismo, no âmbito acadêmico, datam apenas há algumas décadas.

Ainda que não seja um objeto de estudo em destaque da Sociologia, o turismo e o lazer tendem a ser, em face do crescente volume do setor, categorias a serem exploradas pelos cientistas 
sociais, que poderão encontrar no bojo dos avanços dos estudos e conceitos gerados por acadêmicos desse campo em construção.

Nesse panorama, o turismo cultural apresenta-se como uma seara de potencial interesse sociológico. Uma vez que a motivação do turista dirige-se para conhecer a história ou a cultura de um lugar então desconhecido para ela, na qualidade de turista, a Sociologia pode pensar como uma cidade ou região, por exemplo, constrói-se como cenário turístico, o que traz não só novos contextos econômicos, mas também sociais e culturais. Envolve, assim, engendrar um determinado lugar como um lócus de cultura ou história ou tirar do anonimato ou do esquecimento um lugar para fazê-lo viável do ponto de vista do turismo.

O turismo cultural é introduzido nesse contexto como uma possibilidade para muitos municípios brasileiros, em especial aqueles que conservam em seus limites geográficos um acervo e patrimônio material e/ou imaterial que colaboram para visualizar o Brasil colonial, como é o caso de Ouro Preto, Tiradentes, Petrópolis, entre outras cidades.

Na obra Cultura e Turismo: discussões contemporâneas (2007), de Margarita Barretto, o turismo ganha uma conotação de relevância social e cultural, que se constrói como realidade por meio de ações articuladas de diversas instâncias, governamentais ou não, as quais tendem transformar um lugar em espaço turístico.

O turismo cultural envolve memória social. Logo, podese supor que a memória social de um determinado grupo social apresenta um conjunto de imagens e símbolos que são utilizados na esfera local para as ações de promoção turística. Assim, a recuperação de informações, dados históricos, bem como a identificação de patrimônios (material e imaterial) constitui parte primária em um planejamento eficiente no que se refere ao setor turístico em uma cidade que lança-se para o turismo cultural.

Cada cidade ou região abarca uma série de costumes e tradições que sedimentam-se em grupos diversos. Essa diversidade, uma vez reconhecida, também pode ser transformada em atrativo, segundo Halbwachs (2006, p. 159):

O lugar ocupado por um grupo não é como um quadro-negro no qual se escreve e depois se apaga números e figuras. Como a imagem do quadro-negro poderia recordar o que nele traçamos, se o quadro-negro é indiferente aos números e se podemos reproduzir num mesmo quadro as figuras que bem entendemos? Não. Mas o local recebeu a marca do grupo, e vice-versa. Todas as ações do 
grupo podem ser traduzidas em termos espaciais, o lugar por ele ocupado é apenas a reunião de todos os termos.

Desse modo, a realização de festas culturais, rememorativas da imigração ou da cultura imigrante, evoca a memória social da imigração como um aspecto a ser dialogado na esfera cultural e social, o que coloca diante da sociedade treze-tilense o desafio de catalogar os lugares de memória, em outras palavras, as marcas consideradas importantes pelo grupo, bem como criar e/ou recuperar datas e eventos, que rememorem a imigração destes para o Brasil.

Treze Tílias é uma cidade que soube aproveitar suas potencialidades turísticas, ao perceber que sua história e suas memórias tinham sentido não só para si, mas que poderiam ser introduzidas no turismo cultural, acrescido de sua bela paisagem natural e de sua gente empreendedora.

\section{Considerações finais}

Treze Tílias contracena bem com a articulação da lembrança como um eixo organizativo de seu passado, presente e futuro. Lembrar Andreas Thaler na cidade é empreender um caminho para ela própria, cuja economia encontra-se muito direcionada para o turismo cultural. Os monumentos, os imóveis, as festas, os eventos culturais circundam a referência local, que é o Andreas Thaler, e apontam para as ações dos familiares descendentes, muitos dos quais são proprietários de estabelecimentos comerciais que zelam pela memória local da qual eles também são parte.

O desafio apresentado é manter as tradições locais ante a chegada de outros grupos, colocando em disputa não só a memória, mas a necessidade de dialogar com outras memórias, bem como resgatar eventuais capítulos esquecidos da história de Treze Tílias. O importante na construção e na manutenção de uma memória social não é exatamente concentrar-se no que de fato aconteceu no passado de determinada localidade, mas como esta se relaciona com esse passado. Por detrás desse relacionamento é possível enveredar como determinadas articulações estão entranhadas em uma sociedade e servem de fundamento para construir a identidade local.

Os heróis do passado ou aqueles que são trazidos a essa condição são essenciais no processo de construção de uma memória social que se perpetua no presente e no futuro. Assim, 
cabe considerar que Treze Tílias se faz e refaz em sua memória, que oportuniza elencar para si o que deve ou precisa ser lembrado. O turismo cultural retroalimenta essa memória social que, não menos, reacende o sentido de ser treze-tilense, ou seja, lembrar-se de uma saga considerada vitoriosa.

\section{Referências}

ABREU, Regina. Patrimônios etnográficos e museus: uma visão antropológica. In: ABREU, Regina; DODEBEI, Vera. E o patrimônio? Rio de Janeiro: Contra capa/ Programa de Pós-graduação em Memória Social da universidade Federal do Estado do Rio de Janeiro, 2008.

ANDERSON, Benedict. Comunidades imaginadas: reflexões sobre a origem e difusão do nacionalismo. São Paulo: Companhia das Letras, 2008.

BARRETTO, Margarida. Cultura e turismo: discussões contemporâneas. São Paulo: Papirus, 2007.

CASTELLS, Manuel. O Poder da identidade. SP: Paz e Terra, 2008.

DUMAZEDIER, Joffre. Lazer e cultura popular. São Paulo: Perspectiva, 1976.

Sociologia empírica do Lazer. São Paulo: Perspectiva, 1999.

HALBWACHS, Maurice. A Memória coletiva. São Paulo: Centauro, 2006.

LE GOFF, Jacques. História e memória. Campinas: Editora da Unicamp, 1990.

MARTIN, Reiter, OSL, Monika; HUMER, Andreas. 75 anos Dreizehnliden - Treze Tílias. Treze Tílias: Visare Editora e Artes Gráficas Ltda, 2011.

Organização Mundial do Turismo. Compilación de las estadísticas del gasto turístico. Manual Técnico n. 2, 1995.

PARK, Robert.A cidade: sugestões para investigação do comportamento humano no meio urbano. In: VELHO, Octávio Guilherme (Org.). O fenômeno urbano. 4. ed. Rio de Janeiro, 1987, p. 26-67.

POLLAK, Michael. Memória, Esquecimento, Silêncio. Estudos 
Históricos. Rio de Janeiro: Cpdoc/Fundação Getúlio Vargas. v. 2, n. 3, 1989. p. 3-15.

Memória e Identidade Social. Estudos Históricos. Rio de Janeiro: Cpdoc/Fundação Getúlio Vargas. v. 10, n. 3, 1992.

\title{
TREZE TÍLIAS: ARTICULATIONS BETWEEN SOCIAL AND CULTURAL TOURISM
}

\begin{abstract}
City Treze Tílias (SC) exemplifies well about the relation between social memory and cultural tourism like one bridge, where the memories, silences and narratives exists in one society. Founder this colony, Andreas Thaler's name converges this interation, developing the city, formed by Thaler's descendents and other families. In this perspective, through an ethnographic and bibliographic aspects, this article discusses briefly the categories social memory and cultural tourism in respect to Treze Tílias.
\end{abstract}

Keywords: Treze Tílias. Cultural Tourism. Social Memory. Andreas Thaler. 